\title{
Activated Carbon from Bamboo and Banana Wood Fibers as Adsorbent Materials for the Removal of Oil Samples
}

\author{
Oluka N. Ngofa ${ }^{1}$, Efstathios V. Liakos ${ }^{1}$, Antonios N. Papadopoulos ${ }^{2}$, George Z. Kyzas ${ }^{1, *}$ (D) \\ 1 Department of Chemistry, International Hellenic University, Kavala 65404, Greece; oluka4freedom@yahoo.com \\ (O.N.N.); stathilas@gmail.com (E.V.L.); \\ 2 Department of Forest and Natural Environment Science; International Hellenic University, Kavala 65404, Greece; \\ antpap@for.ihu.gr (A.N.P.); \\ * Correspondence: kyzas@chem.ihr.gr (G.Z.K.);
}

Scopus Author ID 17345938100

Received: 20.05.2021; Revised: 15.06.2021; Accepted: 18.06.2021; Published: 24.06.2021

\begin{abstract}
Over the past years and present, the expanding number of oil spills occurrences has gotten an overwhelming chemical test to the marine or oceanic environment, and the environmental issues around the globe are becoming more problematic and more acute, be it oil spills or effluents caused by oil and gas or petrochemical industries. The main point of this current investigation is the synthesis of activated carbon (AC) from various agricultural waste materials, bamboo, and banana fibers, as one of the most promising methodologies or applications in treating oil spills constitutes high sorption capacity. The physicochemical feature of the synthesized AC samples was analyzed by FTIR spectra and $\mathrm{N}_{2}$ physisorption. More specifically, the AC samples derived from bamboo (BAMB-AC) at activation temperature $550{ }^{\circ} \mathrm{C}$ indicate the highest specific surface area $\left(2,760.47 \mathrm{~m}^{2} / \mathrm{g}\right)$, and sorption capacity at $3.3678 \mathrm{~g} / \mathrm{g}$ with the total pore volume, mesopore volume, external surface area being 3.364 $\mathrm{cm}^{3} / \mathrm{g}, 1.811 \mathrm{~cm}^{3} / \mathrm{g}$, and $1,601.634 \mathrm{~m}^{2} / \mathrm{g}$, respectively, and maximum oil sorption capacity at $4.418 \mathrm{~g} / \mathrm{g}$ for BANA-AC with activation ratio $7: 1\left(\mathrm{H}_{3} \mathrm{PO}_{4}\right)$, and surface area at $2,172.234 \mathrm{~m}^{2} / \mathrm{g}$.
\end{abstract}

Keywords: bamboo; banana fiber; activated carbon; absorption; oil spills.

(C) 2021 by the authors. This article is an open-access article distributed under the terms and conditions of the Creative Commons Attribution (CC BY) license (https://creativecommons.org/licenses/by/4.0/).

\section{Introduction}

Oil spills in the ecosystem have a disastrous consequence for society, environmentally, economically, and socially because of accidents that occur during the exploration, exportation of crude oil, transportation of the raw products. These products that contained harmful components in the crude oil as hydrocarbon usually are consisted of oxygen (0\%-3.5\%), nitrogen $(0 \%-0.5 \%)$, sulfur $(0 \%-6 \%)$, with low degrees, and a few heavy metals $[1,2]$.

Environmental contamination and its decrease have drawn sharp consideration for quite a while [3]. The issue of eliminating contaminations from seawater and wastewater has developed with the fast-growing industrial activity [4]. Oil, heavy metals, and different salts are poisonous (toxic) to many organisms, and for this reason, it is important to apply effective techniques to minimize the impact on the environment $[5,6]$.

Crude oil is a truly important asset for the creation of energy and numerous synthetics. In any case, carelessness during the phases of extraction, move, preparing, stockpiling, and utilization can cause ecological contamination that is more regularly extreme and unsalvageable [7,8]. Oil implies petroleum in any structure, including unrefined petroleum known as crude oil, sludge, oil refuse, fuel oil, and refined items (other than petrochemicals) 
$[9,10]$. Of exceptional interest, the motivation behind oil spill contamination adrift is unrefined oils and refined items. Hydrogen and carbon are the most significant and predominant components, including up to $98 \%$ of crude oils and $100 \%$ of many refined items $[11,12]$.

Oil slick mishaps all over the globe, for quite a long time, have pushed researchers to track down a prompt recovery innovation for the fast expulsion of spilled oil from marine regions. The oil slick disaster that occurred on, 20th of April 2010 at the Deepwater Horizon oil plant in the Gulf of Mexico is up to now viewed as the biggest spill in U.S. waters, covering up the 1989 Exxon Valdez spill [13,14].

The environmental issues caused by oil spills around the globe are becoming more problematic, more acute, and one of the most successful and promising methodologies or applications in treating oil spill pollutants is the adsorption technique [15-18]. Various investigations on adsorption properties have been carried out, and most specifically, the lowcost absorbents are the most encouraging for adsorption applications [19,20].

Wood sawdust is not just bountiful, but it is also a systematic adsorbent that can be used successfully for numerous types of toxins, such as oil, heavy metals, salts, etc. [21,22].

Numerous "agricultural by-products" are next to zero financial worth, and a few as for example, sawdust, which are accessible in enormous amounts in timber plants, are frequently present a removal issue $[23,24]$. The utilization of sawdust for eliminating poisons would profit both the wood agriculture and the environment. A promising opportunity for another market will be opened for the sawdust [23,25,26].

One of the most effective applications in oil spill removal from oceans and generally the ecosystem is the adsorption onto AC derived from agricultural wastes. Adsorption, particularly adsorbents, utilizing wood sawdust in the readiness of AC for oil spill removal, possibly can be used further for pharmaceutical removal and heavy metals. [27-31].

The critical factor in the utilization of $\mathrm{AC}$ in remediation and decontamination advances is to utilize the most suitable essential source to set up the AC with the highest specific SA, suggesting the highest decontaminative ability, lower temperature of activation (operating costs and lower energy), higher yields, and resulting in high specific SA, and microporosity is the advantages of chemical activation include activation in a shorter duration [32].

The high cost for the purchase of activating agents and the amount of deionized water that is used to remove process-generated impurities in chemical activation are the disadvantages, such as the purchase of phosphoric acid $\left(\mathrm{H}_{3} \mathrm{PO}_{4}\right)$. In addition, the use of $\mathrm{H}_{3} \mathrm{PO}_{4}$ can lead to the development of both micropores and mesoporous structures in the yielding AC [33].

The synthetic compounds and instruments utilized in this research paper tests were specifically indicated, and the test plan technique utilized was clarified in subtleties. Furthermore, the "chemical-activation" strategy utilized for AC synthesis was clarified or explained, and the strategies and methods utilized for the "characterization" process of ACs obtained were given $[34,35]$.

\section{Materials and Methods}

All the chemical reagents utilized in this research were of logical evaluation of analytical grade. The synthetic materials were collected from local agro-industry and stored in the Hephaestus advanced laboratory in international Hellenic University Kavala, Greece, for further investigation. The chemical reagent used is Phosphoric acid $\left(\mathrm{H}_{3} \mathrm{PO}_{4}, 85\right.$ wt.\%) which was purchased from Fisher chemical and utilized to synthesize AC. 


\subsection{Synthesis of bamboo and banana fiber AC.}

Bamboo and banana fibers were utilized for the synthesis of BAMB-AC, and BANA$\mathrm{AC}$, respectively. Initially, the bamboo (BAMB) was washed with deionized $\mathrm{H}_{2} \mathrm{O}$ in other to remove the impurities of inorganic. Then, they were dried at $110^{\circ} \mathrm{C}$ for 24 hours, in an oven, in other to eliminate the moisture content. After the process, the obtained biomass was ground using a mortar and sieved to obtain particles with a $0.45-0.15 \mathrm{~mm}$ size. The BAMB and BANA, respectively, were chemically activated with $\mathrm{H}_{3} \mathrm{PO}_{4}$ at ratios 5:1 \& 7:1 (chemical agent: biomass precursor).

Specifically, for both cases, $30 \mathrm{~g}$ of dry BAMB or BANA were placed in a vial and mixed for $24 \mathrm{~h}$ under continuous agitation of $400 \mathrm{RPM}$, at the appropriate impregnation ratio (5:1 \& 7:1). The activation agent was $\mathrm{H}_{3} \mathrm{PO}_{4}$ (a basic aqueous solution), and the process was achieved at ambient temperature. After the activation process, the obtained chemically treated biomasses were dried at $110{ }^{\circ} \mathrm{C}$ for $24 \mathrm{~h}$, to remove the residue $\mathrm{H}_{2} \mathrm{O}$. The activation/carbonization process was achieved by thermal treatment of the obtained solid residues at 450 and $550{ }^{\circ} \mathrm{C}$ (heating rate $10{ }^{\circ} \mathrm{C} / \mathrm{min}$ ) in a pyrolysis oven within $1 \mathrm{~h}$, under $\mathrm{N}_{2}$ flow $30 \mathrm{STP} \mathrm{cm}^{3} / \mathrm{min}$ (pure: $99.999 \%$ ). After the carbonization process of the yielded material, the obtained residue products were basically cooled down at ambient temperature and thereafter were washed with $25 \% \mathrm{HCl}\left(37\right.$ wt. $\%$ ) and then with deionized $\mathrm{H}_{2} \mathrm{O}$ until reaching the neutral filtrate of $\mathrm{pH}(6-7)$. Finally, the yielded material was placed in an oven and was dried at $110{ }^{\circ} \mathrm{C}$ for $24 \mathrm{~h}$ to obtain the final dry sample referred to as BAMB-AC. AC which derived from the banana fiber was synthesized by following the same synthetic protocol but using $30 \mathrm{~g}$ of banana fiber (BANA) while the final obtained material is referred to as BANAAC.

Table 1. Yield of AC and several experimental parameters which obtained during the experimental process.

\begin{tabular}{l|c|c|c|c|c|c|c}
$\begin{array}{l}\text { Biomass } \\
\text { precursor }\end{array}$ & $\begin{array}{c}\text { Chemical } \\
\text { agent }\end{array}$ & $\begin{array}{c}\text { Impregnation } \\
\text { ratio (chemical } \\
\text { agent:biomass } \\
\text { precursor) }\end{array}$ & $\begin{array}{c}\text { Weight before } \\
\text { impregnation } \\
(\mathbf{g})\end{array}$ & $\begin{array}{c}\text { Weight after } \\
\text { impregnation } \\
(\mathbf{g})\end{array}$ & $\begin{array}{c}\text { Pyrolysis } \\
\text { temperature } \\
\left({ }^{\circ} \mathbf{C}\right)\end{array}$ & $\begin{array}{c}\text { Activated } \\
\text { carbon } \\
(\mathbf{g})\end{array}$ & $\begin{array}{c}\text { Yield } \\
(\%)\end{array}$ \\
\hline Bamboo & $\mathrm{H}_{3} \mathrm{PO}_{4}$ & $5: 1$ & 30 & 123.0 & 450 & 5.29 & 17.63 \\
\hline Bamboo & $\mathrm{H}_{3} \mathrm{PO}_{4}$ & $5: 1$ & 30 & 130.15 & 550 & 5.47 & 18.23 \\
\hline $\begin{array}{l}\text { Banana } \\
\text { Fiber }\end{array}$ & $\mathrm{H}_{3} \mathrm{PO}_{4}$ & $5: 1$ & 30 & 128 & 450 & 3.86 & 12.87 \\
\hline $\begin{array}{l}\text { Banana } \\
\text { Fiber }\end{array}$ & $\mathrm{H}_{3} \mathrm{PO}_{4}$ & $5: 1$ & 30 & 132 & 550 & 3.76 & 12.53 \\
\hline Bamboo & $\mathrm{H}_{3} \mathrm{PO}_{4}$ & $7: 1$ & 30 & 157.36 & 450 & 5.68 & 18.93 \\
\hline Bamboo & $\mathrm{H}_{3} \mathrm{PO}_{4}$ & $7: 1$ & 30 & 168.3 & 550 & 4.20 & 14 \\
\hline $\begin{array}{l}\text { Banana } \\
\text { Fiber }\end{array}$ & $\mathrm{H}_{3} \mathrm{PO}_{4}$ & $7: 1$ & 30 & 163.3 & 450 & 3.20 & 10.67 \\
\hline $\begin{array}{l}\text { Banana } \\
\text { Fiber }\end{array}$ & $\mathrm{H}_{3} \mathrm{PO}_{4}$ & $7: 1$ & 30 & 175.0 & 550 & 3.00 & 10 \\
\end{tabular}

\subsection{Adsorption experiments.}

BAMB-AC and BANA-AC were applied to adsorption experiments to find the efficiency of those materials to remove diesel oil.

This progression was carried out after literature reviews expressing diverse biomass materials using AC synthesized as processors for potential cleanup for oil slicks. Accordingly, AC tests sorption with diesel oil were conducted. These present examinations' fundamental advances are moderately adopted using BAMB-AC and BANA-AC that comprises different activation ratios of 5:1 and 7:1 and temperatures of activation $\left(450 \& 550{ }^{\circ} \mathrm{C}\right)$. Each of the adsorbent samples weighted $0.5 \mathrm{~g}$, while the amount of diesel oil was $50 \mathrm{ml}$. In addition, the 
flasks that were utilized were conical with a volume of $100 \mathrm{ml}$ each. The contact time between the adsorbent and model pollutant was $24 \mathrm{~h}$. Diesel oil measured $(50 \mathrm{ml})$ was poured into the aforementioned flasks, and each with of AC samples (0.5) was inserted inside the flasks in the presence of the model pollutant. Moreover, these samples were then placed in an $\mathrm{H}_{2} \mathrm{O}$ bath at a constant temperature $\left(25^{\circ} \mathrm{C}\right)$. However, after the estimated contact time has been achieved, the filter paper containing each of the samples of BAMB-AC and BANA-AC with oil was recovered and placed on a large filter paper for the drying process. The drying process was achieved at $80{ }^{\circ} \mathrm{C}$ for $72 \mathrm{~h}$.

After the dehydration process, the obtained AC samples were measured in other to obtain the amount of oil adsorbed. It ought to be noticed that these experiments of sorption, are likewise rehashed multiple times to keep away from experimental errors. Consequently, the result for each sample conducted for $24 \mathrm{hrs}$ will be derived from the normal of the batches prepared to acquire a capacity of sorption that is as close as conceivable to reality. Each of the experiments was performed, and the sorption capacities were calculated using the following eq. 1:

$$
\text { Oil sorption capacity }=\frac{\text { weight of adsorbed oil }}{\text { weight of sorbents }}
$$

\subsection{Characterization techniques.}

The functional groups of the synthesized AC samples were studied with the utilization of the FTIR-spectrometer (Perkin Elmer FT-IR/NIR spectrometer Frontier, New York, NY, USA). The spectra were recorded at a range from 4000 to $600 \mathrm{~cm}^{-1}\left(2 \mathrm{~cm}^{-1}\right.$ as the resolution and a total of 32 scans) and presented with baseline correction (transmittance mode) [36]. The "Brumauer-Emmett-Teller" (BET) model was utilized in calculating the BET-specific surface areas (SA). The external SA, micropore SA, and micropore volume were calculated with the tplot method. The SA of ACs was estimated at $77 \mathrm{~K}$ from the nitrogen adsorption/desorption isotherms by employing a Quanta-chrome-analyzer (Nova 4200e, NY, USA). The relative pressure factor $(\mathrm{p} / \mathrm{p} 0)$ was from 0.005 to 0.985 for all cases of the synthesized samples. Preceding the estimations of gas adsorption, the AC was degassed at $250{ }^{\circ} \mathrm{C}$ in the case of impregnation ratio $5: 1$, and at $300{ }^{\circ} \mathrm{C}$ for impregnation ratio $7: 1$ in vacuum states of 0.1 torrs for $20 \mathrm{~h}$, respectively. The BET SA was estimated through the standard BET condition. The absolute total volume of pores was resolved at around $0.985(\mathrm{p} / \mathrm{p} 0)$ to ensure that all pores will be totally loaded up with $\mathrm{N}_{2}$ gas [37]. Pore size distribution, total pore volume for all instances of $\mathrm{AC}$ were gotten from the $\mathrm{N}_{2}$ adsorption isotherms through the software provided, which utilizes the BJH hypothesis. The estimation of external SA, and micropore volume was accomplished with the t-plot methodology [38]. The micropore surface area was also dictated by distinction. Origin-Lab 2018 was utilized for data analysis and graphing of samples.

\section{Results and Discussion}

\subsection{FTIR before and after oil adsorption.}

As shown in Figure 3 ( $\mathrm{a}$ and $\mathrm{c}$ ), the FTIR analysis for synthetic BAMB-AC, BANAAC obtained at different ratio $(5: 1$ and $7: 1)$ at temperature $\left(450{ }^{\circ} \mathrm{C}\right.$ and $\left.550{ }^{\circ} \mathrm{C}\right)$ revealed peaks at transmittance band $3420 \mathrm{~cm}^{-1}-3200 \mathrm{~cm}^{-1}$ which are attributed to the $(\mathrm{O}-\mathrm{H}$ or $\mathrm{OH})$ stretching vibration of "hydroxyl groups" [39-41]. 
The asymmetry and position of bands at lower wavenumbers indicating the presence of strong "hydrogen bonds". The line at $3000 \mathrm{~cm}^{-1}$ can be considered useful because it indicates the "border" within alkene $(\mathrm{C}-\mathrm{H})$ above and alkane $(\mathrm{C}-\mathrm{H})$ below $3000 \mathrm{~cm}^{-1}$, which helps determine the present bonds.

Absorption bands from "2920 $\mathrm{cm}^{-1}$, and $2850 \mathrm{~cm}^{-1 "}$ are attributed to the aliphatic nature, and the sharp peaks witness around the spectrum region within $1744 \mathrm{~cm}^{-1}$ to $1698 \mathrm{~cm}^{-1}$ indicate extended vibrations of carbonyl groups $[\mathrm{C}=\mathrm{O}]$ or aldehydes, ketones, lactones. These peaks at this region may be considered the strongest peaks in the entire spectrum from what is observed. They are "Sword-like" which appears relatively narrow [42-46].

The expansive band at $1300-1000 \mathrm{~cm}^{-1}$ is generally found with "oxidized carbons", and has been assigned to $[\mathrm{C}-\mathrm{O}]$ stretching vibration in "acids", "phenols", "ethers", and alcohols or potentially esters groups $[37,47]$. At low "wavenumber" points, the peak at 866 to $750 \mathrm{~cm}^{-1}$ could be attributed to the out-of-plane deformation mode or bending absorption of $\mathrm{C}-\mathrm{H}$ in the aromatic rings [48].

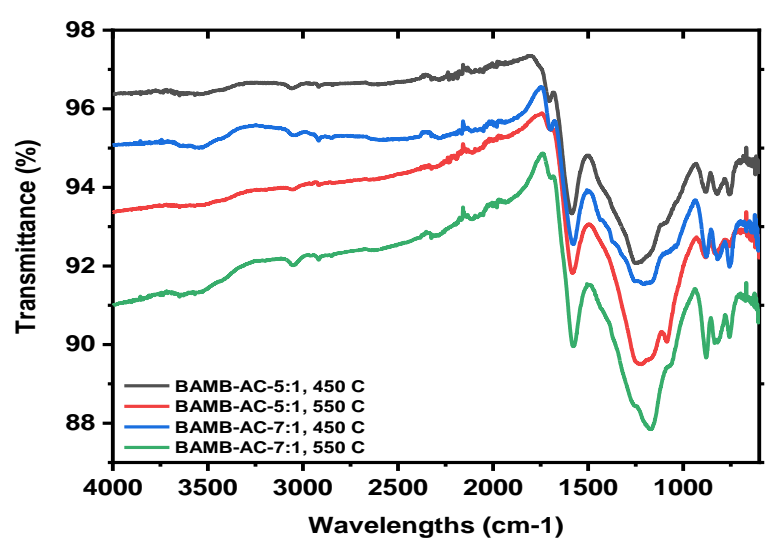

(a)

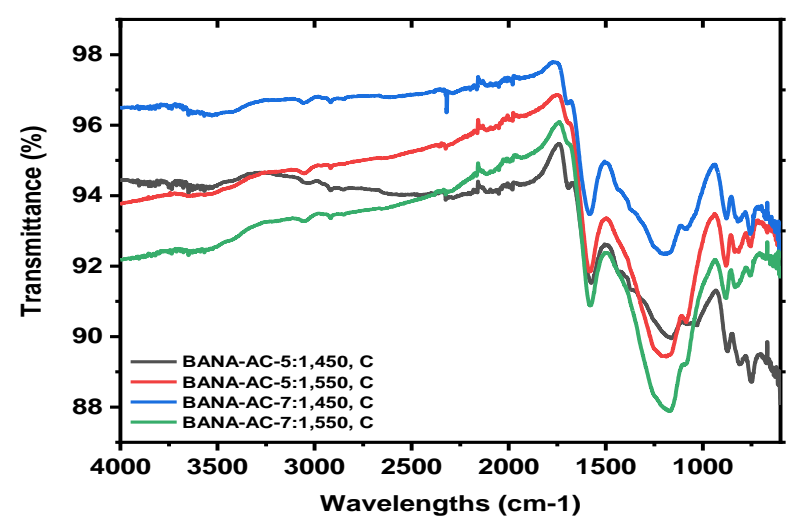

(c)

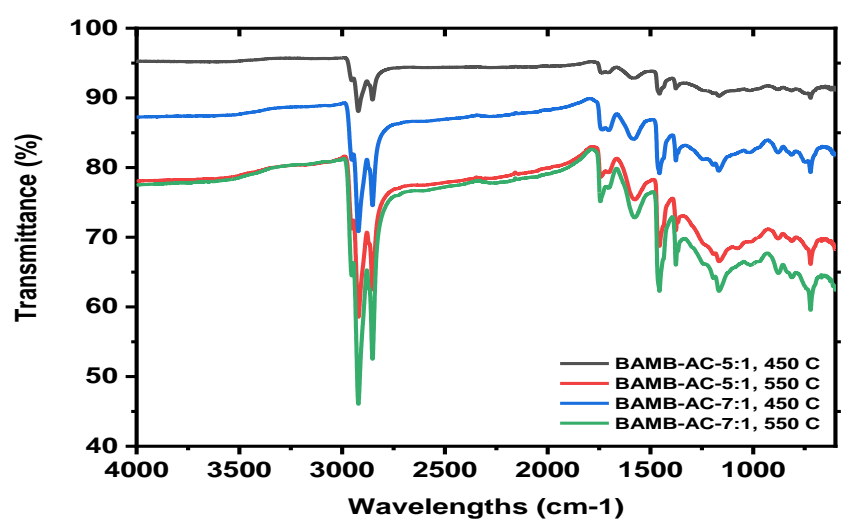

(b)

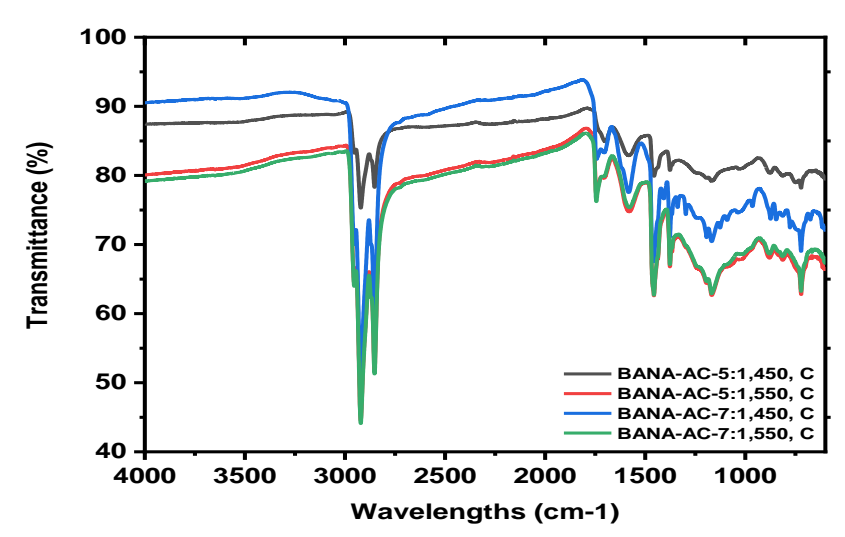

(d)

Figure 1. FTIR spectra studied samples; (a \& b) shows before and after oil adsorption for BAMB-AC; (c \& d) Presents the before and after-oil adsorption for BANA-AC.

The batch adsorption experiments were conducted as stated in the above statements with BAMB-AC and BANA-AC samples. The samples indicate 24 hours of oil adsorption process, which were left in the shaker bath after being dried, and results of each batch experiment were analyzed using FTIR analysis to determine the absorption capacity of black BAMB-AC, and BANA-AC already undergoes oil adsorption. 
In Figure $1 \mathrm{~b}$ and $\mathrm{d}$ are presented the FTIR spectra of BAMB-AC, BANA-AC, after oil absorption for $24 \mathrm{hrs}$. From a close interpretation of the spectra, it can be observed that some changes occur in the bands of the Transmittance (\%), with slight shifts in the location of the bands. This change can be proposing that the composition of oil has affected the position of the bands and shifts in the bands due to some acid composition, both BAMB-AC, and BANAAC demonstrated intense peaks changes from 2953;2921;2852 $\mathrm{cm}^{-1}$ to $1744-1698 \mathrm{~cm}^{-1}$. The slight difference was so obvious since it was noticeable to have a maximum adsorption capacity around the bands of both samples. Owing to asymmetrical and symmetrical vibration of alkyl chain moieties, the sharpness of peak intensity was an increase from 2921 to $2953 \mathrm{~cm}^{-1}$ for BAMB-AC and BANA-AC $\left(7: 1,550^{\circ} \mathrm{C}\right)$, the peaks indicate that it interacts with the functional group of the oil model pollutant and has good comparison with the FTIR spectra of BAMBAC, BANA-AC $\left(7: 1450{ }^{\circ} \mathrm{C}\right.$, and 5:1 $\left.550{ }^{\circ} \mathrm{C}\right)$. Furthermore, the sharpness of peaks after oil adsorbed at peaks from 2324, 2283, 1990, 1579, 1698, 1735, 1456, 1077, 877, and $720 \mathrm{~cm}^{-1}$ and clearly illustrate that oil molecules interacted with the functional affirmation group of BAMB-AC and BANA-AC. However, the contact time (24hr) played an important role at the beginning of the adsorption process and was found to influence oil recovery significantly.

To understand the adsorption interaction among the PRM, FTIR spectra after adsorption were taken. So, after PRM adsorption, the band at about 2953, 2951, and 2852 revealed a higher intensity, while a new band at about 2324; 2283; appeared. (Figure 3). These findings are attributed to the interaction with PRM molecules, in addition, the band at $1579 \mathrm{~cm}^{-}$ ${ }^{1}$ became more intense, and a new band at 1698 appeared. On the other hand, the band at 2075 , 1990,1195, at 1168 were eliminated, depicting that these groups reacted with the RMP molecules. The band at 877 (out-of-place bending) and $612 \mathrm{~cm}^{-1}(\mathrm{O}-\mathrm{H})$ shifted to 877 and 667 $\mathrm{cm}^{-1}$.

Table 2. Main functional groups derived from the studied BAMB-AC and BANA-AC before and after oil absorption.

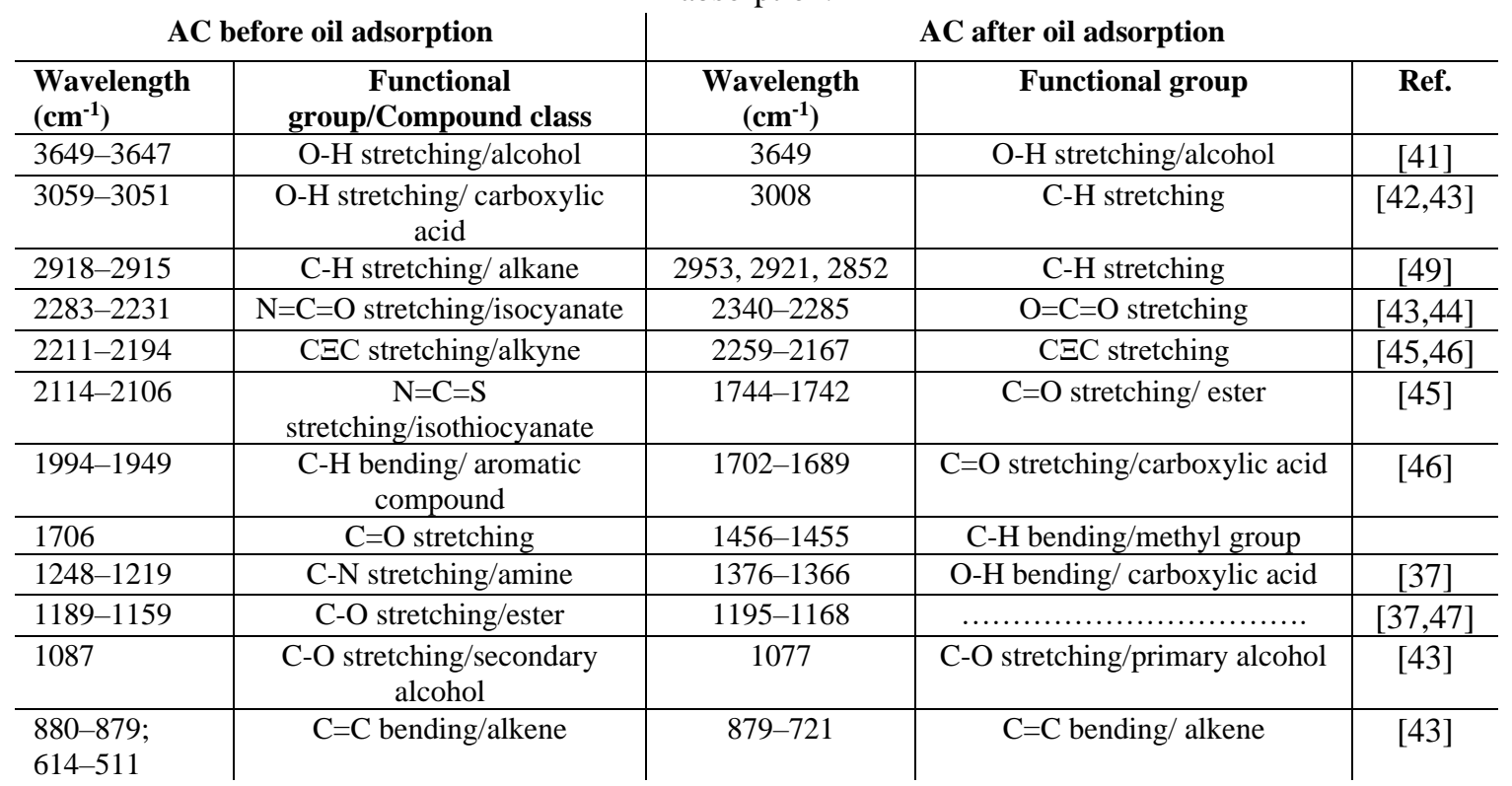

\subsection{Oil adsorption.}

Figure 2 a indicates that between BAMB-AC, and BANA-AC, which were impregnated with $\mathrm{H}_{3} \mathrm{PO}_{4}$ at impregnation ratio 5:1, with activation temperature of $450{ }^{\circ} \mathrm{C}$ under $\mathrm{N}_{2}$ flow, shows a different surface area with the blue point; BANA-AC indicating a lower SA at 771.45 
$\mathrm{m}^{2} / \mathrm{g}$ compared to the black point; BAMB-AC that presents a higher SA at $1719.841 \mathrm{~m}^{2} / \mathrm{g}$. The weight of samples changes from the initial value of $0.5 \mathrm{~g}$ after the oil adsorption experiment. Both samples show a higher value of $1.0954 \mathrm{~g}$ and $1.6185 \mathrm{~g}$ after $24 \mathrm{hrs}$ contact time. BAMBAC indicated a higher weight which shows that it adsorbed more oil than BANA-AC. Similar cases were noticeable in Figure $2 \mathrm{~b}$ with activation temperature of $550{ }^{\circ} \mathrm{C}$ but present different views, which indicate that at blue point 5:1 with BAMB-AC presenting higher SA at 2760.447 $\mathrm{m}^{2} / \mathrm{g}$, with weight after oil adsorbed at $1.7839 \mathrm{~g}$, more than yellow points; BANA-AC demonstrating a SA at $1331.578 \mathrm{~m}^{2} / \mathrm{g}$, and weight after oil adsorbed at $1.5605 \mathrm{~g}$ from initial $0.5 \mathrm{~g}$ before oil adsorption.

In Figure $2 \mathrm{c}$ and d, BAMB-AC, and BANA-AC, which was impregnated with $\mathrm{H}_{3} \mathrm{PO}_{4}$ at ratio $7: 1$ with temperature $\left(450{ }^{\circ} \mathrm{C}\right)$, shows with an increased ratio at the pink point the BANA-AC presents a higher SA at $1,825.313 \mathrm{~m}^{2} / \mathrm{g}$, and weight after oil adsorbed at $1.8183 \mathrm{~g}$ compared to BAMB-AC SA of $1,544.920 \mathrm{~m}^{2} / \mathrm{g}$, and weight after oil adsorbed at $1.4748 \mathrm{~g}$ at the green point. This also shows favorable oil adsorption of both AC, but the BANA-AC presents higher adsorption efficiency due to an increase in the ratio of the activation agents $\left(\mathrm{H}_{3} \mathrm{PO}_{4}\right)$. At activation temperature of $550{ }^{\circ} \mathrm{C}$, red point, BANA-AC demonstrating a higher SA at $2,172.234 \mathrm{~m}^{2} / \mathrm{g}$, weight after oil adsorbed at 2.2090g which show a high SA and weight after oil adsorption than BAMB-AC at the black point with a surface area at $2,151.572 \mathrm{~m}^{2} / \mathrm{g}$, and with weight after oil adsorption at $1.4664 \mathrm{~g}$ after $24 \mathrm{~h}$ contact time.

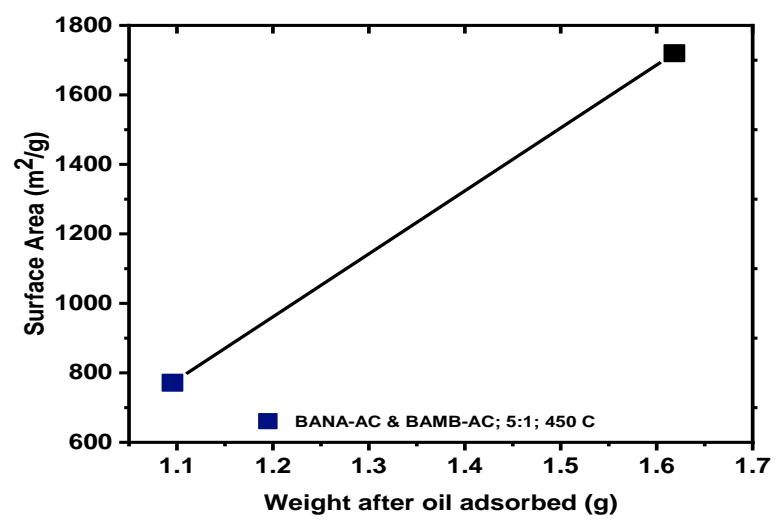

(a)

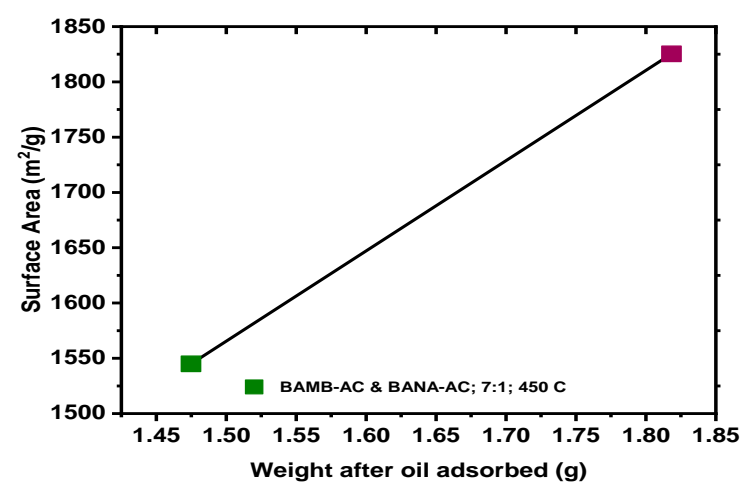

(c)

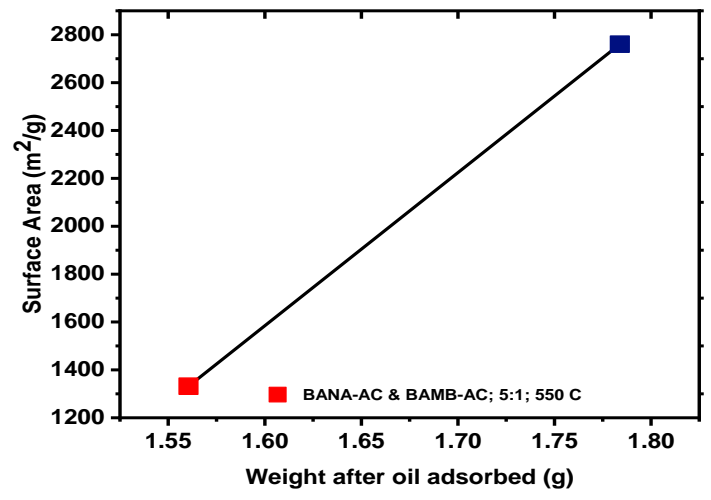

(b)

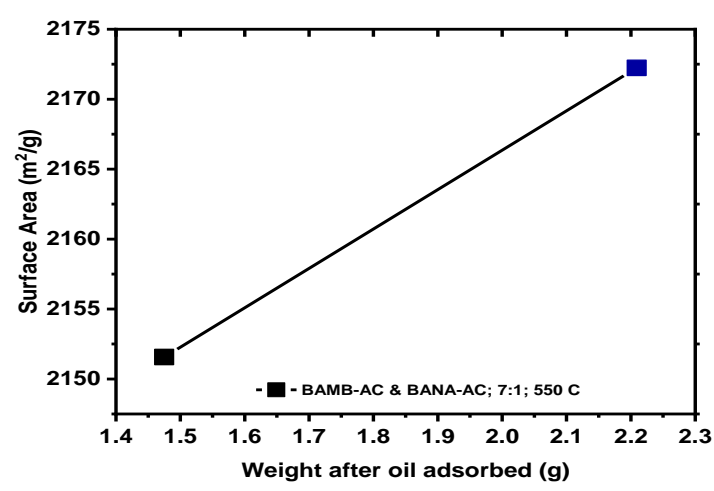

(d)

Figure 2. shown (a \&b) BANA-AC \& BAMB-AC 5:1 450/550 ${ }^{\circ} \mathrm{C}$ that indicates the value of surface area/ weight oil adsorbed; (c \&d) Indicates the value of surface area/ weight oil adsorbed of BAMB-AC \& BANAAC $7: 1450 / 550{ }^{\circ} \mathrm{C}$. 
The capacity of AC absorption in oil, it is to note that all in the batches evidenced a progressive increase of time by increasing adsorption time, to have effective oil recovery, the sorbents' material's need to be able to absorb a high amount of oil pollutants, but low amount of water. These characteristics are basically required in other to offer suitable selective sorption of oil pollutants in water. The observations of very high sorption for BANA-AC, BAMB-AC 5:1;7:1 sample at $550{ }^{\circ} \mathrm{C}$, this behavior represented a selectivity of the absorbent AC for oil recovery. To maximize AC's performance in removing the diesel oil, the hydrophobicity and oleophilicity of the surface need to be enhanced [13,52-54].

\subsection{Effect of contact time.}

The process of oil adsorption was achieved as aforementioned with $0.5 \mathrm{~g}$ of the synthesized AC (BAMB-AC or BANA-AC) and $50 \mathrm{ml}$ of diesel oil using a conical flask. Considering the oil spills are adsorbed by the adsorbent materials for $24 \mathrm{hrs}$ as contact time.

Figure 3 (a) at the navy-blue point shows that BANA-AC has sorption capacity of $2.1908 \mathrm{~g} / \mathrm{g}$, compared to the magenta point of BAMB-AC with a maximum sorption capacity of $3.237 \mathrm{~g} / \mathrm{g}$, with the same ratio of $5: 1$ at activation temperature $450{ }^{\circ} \mathrm{C}$. Furthermore, the results demonstrate that the synthesized adsorbent has a higher removal rate for the case of diesel oil (model pollutant). As seen from the figure, the oil sorption rate through the contact time has a large concentration gradient between solution and oil spill over this period, and it can be observed that from the red and gray point, both ACs have a maximum sorption capacity with the BANA-AC at $3.121 \mathrm{~g} / \mathrm{g}$, compared to BAMB-AC black point with a higher sorption capacity at $3.5678 \mathrm{~g} / \mathrm{g}$ with increasing the activation temperature at $550{ }^{\circ} \mathrm{C}$, and therefore, the sorption capacity is reached to maximum value after $24 \mathrm{hrs}$. The sorption capacity of the AC for oil spills is unchanged by increasing the contact time because the sorbent is saturated, and there is no active site for adsorption.

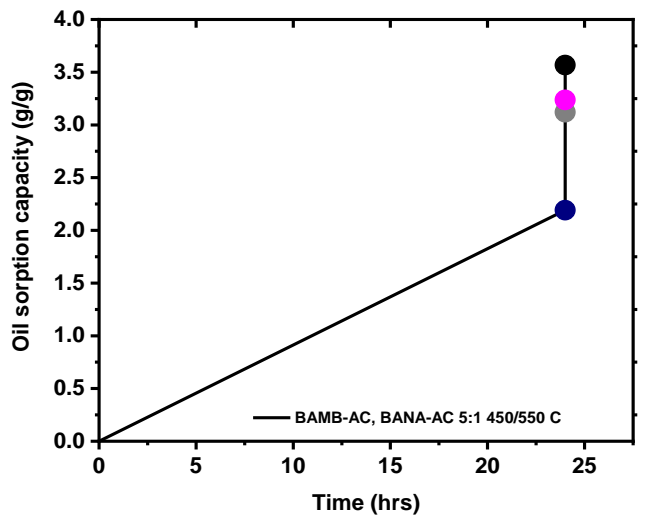

(a)

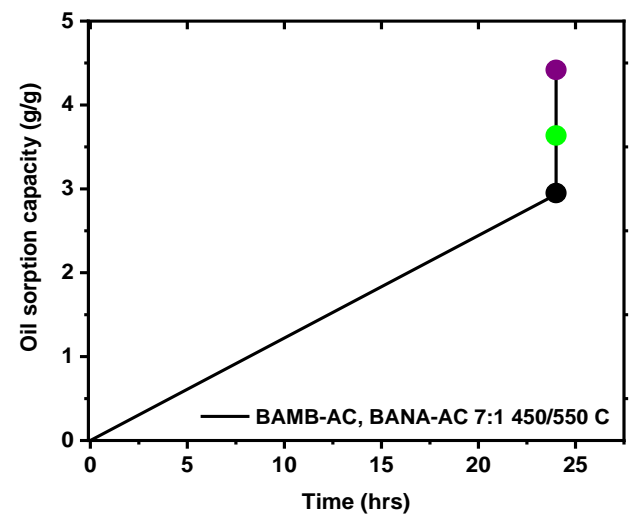

(b)

Figure 3. Contact time effects on the oil adsorption process.

As shown it can be shown in Figure 3 (b), the black points represent the soprtion capacity which was found to be $2.9496 \mathrm{~g} / \mathrm{g}$ for BAMB-AC at $450{ }^{\circ} \mathrm{C}$ and $2.9328 \mathrm{~g} / \mathrm{g}$ at $550{ }^{\circ} \mathrm{C}$ (impregnation with $\mathrm{H}_{3} \mathrm{PO}_{4}$ at ratio 7:1). BANA-AC has the higher maximum sorption capacities at $3.6366 \mathrm{~g} / \mathrm{g}$ and $4.418 \mathrm{~g} / \mathrm{g}$, and since the BANA-AC has the higher oil capacity compared to other samples, and it can be observed that from Figure 1 ( $b$ and d), which was determined by FTIR spectra, because the contact time ( $24 \mathrm{hrs}$.), the temperature of sorption (25 $\left.{ }^{\circ} \mathrm{C}\right)$ played a significant role to determine the parameters. 
Table 3. BAMB-AC \& BANA-AC $(5: 1 \& 7: 1)$ at activation temperature $450{ }^{\circ} \mathrm{C}$ and $550{ }^{\circ} \mathrm{C}$, indicating the weight before and after oil adsorption and surface area, respectively.

\begin{tabular}{l|c|c|c|c|c}
$\begin{array}{l}\text { Activated } \\
\text { carbon }\end{array}$ & $\begin{array}{c}\text { Impregnation } \\
\text { ratio (chemical } \\
\text { agent: biomass } \\
\text { precursor) }\end{array}$ & $\begin{array}{c}\text { Pyrolysis } \\
\text { temperature } \\
\left({ }^{\circ} \mathbf{C}\right)\end{array}$ & $\begin{array}{c}\text { Weight before } \\
\text { oil adsorption } \\
(\mathbf{g})\end{array}$ & $\begin{array}{c}\text { Weight after oil } \\
\text { adsorption } \\
(\mathbf{g})\end{array}$ & $\begin{array}{c}\text { Surface area } \\
\left(\mathbf{m}^{2} / \mathbf{g}\right)\end{array}$ \\
\hline BAMB-AC & $5: 1$ & 450 & 0.5 & 1.6185 & 1719.841 \\
\hline BANA-AC & $5: 1$ & 450 & 0.5 & 1.0954 & 771.45 \\
\hline BAMB-AC & $5: 1$ & 550 & 0.5 & 1.7839 & 2760.447 \\
\hline BANA-AC & $5: 1$ & 550 & 0.5 & 1.5605 & 1331.578 \\
\hline BAMB-AC & $7: 1$ & 450 & 0.5 & 1.4748 & 1544.920 \\
\hline BANA-AC & $7: 1$ & 450 & 0.5 & 1.8183 & 1825.313 \\
\hline BAMB-AC & $7: 1$ & 550 & 0.5 & 1.4664 & 2151.572 \\
\hline BANA-AC & $7: 1$ & 550 & 0.5 & 2.2090 & 2172.234
\end{tabular}

\subsection{BET analysis: $N_{2}$ adsorption-desorption isotherm.}

As depicted in Figure 4, the " $\mathrm{N}_{2}$ adsorption-desorption isotherm" curves of AC obtained from BAMB and BANA for ratios 5:1, and 7:1, and activation temperature $450{ }^{\circ} \mathrm{C}$ and $550{ }^{\circ} \mathrm{C}$ each. Based on IUPAC classifications, a Type I isotherm is associated with microporous structures, and a Type IV isotherm demonstrates a combination of microporous and mesoporous materials. BAMB-AC and BANA-AC revealed that it has "low values of relative pressure" (p/p0), which indicates Type I, and "higher relative pressure" which represent Type IV therefore, both are indicating the mixture of microporous and mesoporous nature [55-57]. I suppose that the below graphs are Type IV an isotherm according to IUPAC 2015

However, the results of different ratios for BAMB-AC and BANA-AC affirmed because of the presence of $\mathrm{H} 3$ and $\mathrm{H} 4$ desorption hysteresis loops that are generally normal for the co-existence of both microporous and mesoporous AC materials. the "hysteresis-loop" is typically brought about by "capillary" condensation in the mesopores of AC materials[58,59].

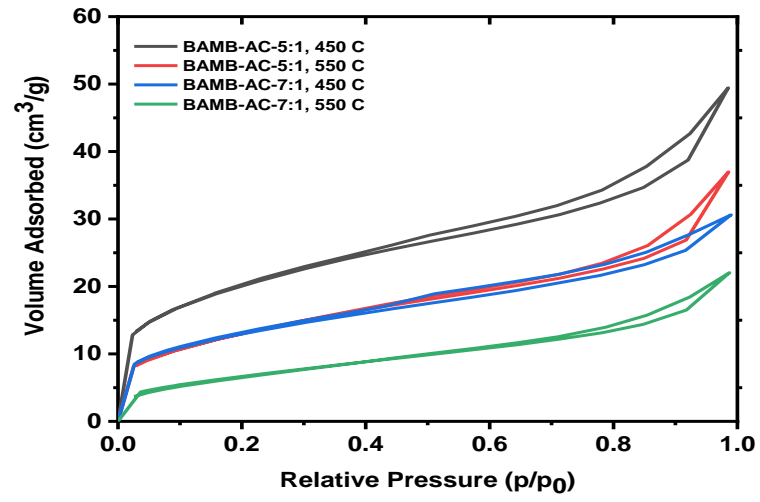

(a)

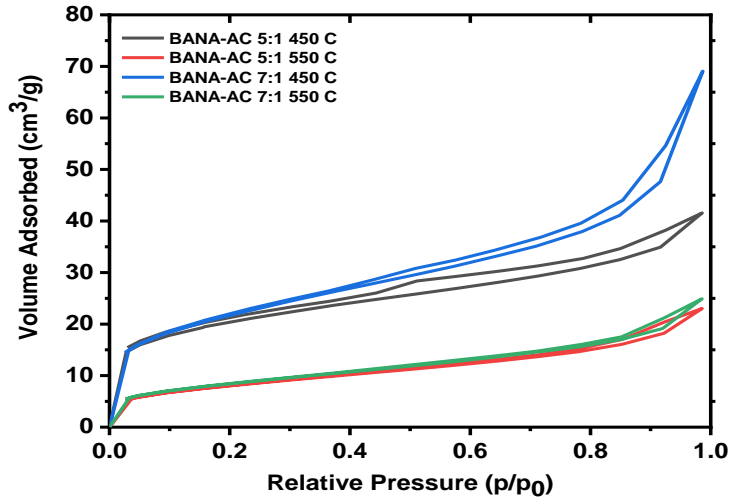

(b)

Figure 4. BET Analysis of samples (a) shows the BANA-AC with each the ratio and temperature; (b) Present for BAMB-AC, which indicate for each of the ratios, and temperatures.

The angle was open within the volume range of $\left(10-20 \mathrm{~cm}^{3} / \mathrm{g}\right)$, relative pressure $(\mathrm{p} / \mathrm{p} 0)$ around 0.1 for BANA-AC-5:1 and BANA-AC-7:1 at $450{ }^{\circ} \mathrm{C}$ with $550{ }^{\circ} \mathrm{C}$ around volume adsorbed range of $(5-10 \mathrm{~cm} 3 / \mathrm{g})$, same applied for BAMB-AC, with rapid adsorption for $\mathrm{N} 2$ onto the micropores. $\mathrm{p} / \mathrm{p} 0>0.1, \mathrm{~N}^{2}$ starts by absorbing the external surface or large pores, and the amount was considerable [60,61]. The close pore structure relationships between two samples could be proved in the specific SA section in Table 4.

As a significant indicator of pore structure attributes, the adsorption capacity of BANAAC was examined in Table 4. The SA determined with the BET methodology, total pore 
volume of BANA-AC samples increased with the increasing activation temperature, and at 450 ${ }^{\circ} \mathrm{C}$ the SA had a maximum of $771.450 \mathrm{~m} 2 / \mathrm{g}$, and which was level off at $550{ }^{\circ} \mathrm{C}$ with a higher $\mathrm{SA}$ of $1825.313 \mathrm{~m} 2 / \mathrm{g}$ with the same ratio of $5: 1$. The same also witness with a ratio $7: 1$. The above table indicates the parameters of BANA-AC samples.

Table 4 shows the indicator of adsorption capacity, pore structure which is attributed to BAMB-AC. The SA determined with the BET methodology (SBET), and total pore volume (Vt) of BAMB-AC increased with the increasing temperature, and at $450{ }^{\circ} \mathrm{C}$ the $\mathrm{SA}$ had a maximum of $1719.841 \mathrm{~m}^{2} / \mathrm{g}$, and which was level off at $550{ }^{\circ} \mathrm{C}$ with higher SA $2,760.447 \mathrm{~m}^{2} / \mathrm{g}$ with the same ratio of 5:1. The same also witness a ratio 7:1 with an increase SA. The above table indicates the difference between each parameter of BAMB-AC samples. The SA of BAMB-AC and BANA-AC 5:1; 7:1 at $550{ }^{\circ} \mathrm{C}$ was discovered to be $(2,760.447 \mathrm{~m} 2 / \mathrm{g}$; $2,172.234 \mathrm{~m} 2 / \mathrm{g}$ ) which is higher than $5: 1$ and $7: 1$ at $450{ }^{\circ} \mathrm{C}$. The total pore volume of BAMBAC 5:1; 7:1 at $550{ }^{\circ} \mathrm{C}$ has a higher volume $3.044 \mathrm{~cm}^{3} / \mathrm{g}, 3.364 \mathrm{~cm}^{3} / \mathrm{g}$, respectively, which affirmed that $\mathrm{H}_{3} \mathrm{PO}_{4}$ might create more pore than other activating agents during the procedure of activation. This could be ascribed to how $\mathrm{H}_{3} \mathrm{PO}_{4}$ impregnation with precursors was more capable of destroying lignin structures and decreasing crystallinities of cellulose, which led to high porosity [62,63]. Micropores and mesopores present in the considered examples were found of the combination of both type I \& IV isotherms and Barrett-Joyner-Halenda (BJH) pore size distribution, which suggests the presence of micropores; micropore SA; micro-pore volume; external SA; mesoporosity; microporosity was resolved utilizing t-plot investigation which was suggested by Lippens and De-Boer, and Table 4 summed it up [63,64].

The AC high adsorption capacity of numerous natural organic mixtures has been broadly studied and demonstrated by numerous investigations. AC that was utilized is powdered AC (PAC). SA of AC is subjected to the activation process and utilized "raw material" surface oxidation which is also a basic factor in enhancing the surface processes. Surface chemistry is perhaps the most significant property that dictate the adsorption system or mechanism and capacity towards various oil pollutants $[63,65,66]$.

Table 4. Characteristics/ Parameters of BAMB-AC and BANA-AC at different impregnation ratios and temperatures.

\begin{tabular}{|c|c|c|c|c|c|c|c|}
\hline Materials samples & $\begin{array}{c}\text { BET Surface } \\
\text { Area } \\
\left(\mathbf{m}^{2} / \mathbf{g}\right)\end{array}$ & $\begin{array}{l}\text { Micropore } \\
\text { Surface } \\
\text { Area }\left(\mathbf{m}^{2} / \mathbf{g}\right)\end{array}$ & $\begin{array}{c}\text { External } \\
\text { Surface Area } \\
\left(\mathbf{m}^{2} / \mathbf{g}\right)\end{array}$ & $\begin{array}{l}\text { Total Pore } \\
\text { Volume } \\
\left(\mathrm{cm}^{3} / \mathrm{g}\right)\end{array}$ & $\begin{array}{l}\text { Micropore } \\
\text { Volume } \\
\left(\mathrm{cm}^{3} / \mathrm{g}\right)\end{array}$ & $\begin{array}{l}\text { Mesopore } \\
\text { Volume } \\
\left(\mathrm{cm}^{3} / \mathrm{g}\right)\end{array}$ & $\begin{array}{c}\text { Mesopore } \\
\text { Volume } \\
\left(\mathrm{cm}^{3} / \mathrm{g}\right)\end{array}$ \\
\hline Bamb-AC-5:1, $450^{\circ} \mathrm{C}$ & 1719.841 & 861.333 & 858.508 & 1.865 & 0.383 & 545.538 & 0.951 \\
\hline Bana-AC- $5: 1,450^{\circ} \mathrm{C}$ & 771.450 & 486.944 & 284.505 & 0.6774 & 0.218 & 218.280 & 0.333 \\
\hline Bamb-AC-5:1, 550 ${ }^{\circ} \mathrm{C}$ & 2760.447 & 1158.813 & 1601.634 & 3.364 & 0.482 & 1007.526 & 1.811 \\
\hline Bana-AC-5:1, $550^{\circ} \mathrm{C}$ & 1825.313 & 671.116 & 1154.197 & 2.282 & 0.303 & 763.616 & 1.409 \\
\hline Bamb-AC-7:1, $450{ }^{\circ} \mathrm{C}$ & 1544.920 & 788.235 & 756.685 & 1.558 & 0.337 & 574.294 & 1.023 \\
\hline Bana-AC- $7: 1,450^{\circ} \mathrm{C}$ & 1331.578 & 465.936 & 865.642 & 1.871 & 0.205 & 532.245 & 1.024 \\
\hline Bamb-AC- $7: 1,550{ }^{\circ} \mathrm{C}$ & 2151.572 & 530.194 & 1621.378 & 3.044 & 0.206 & 1074.824 & 2.398 \\
\hline Bana-AC-7:1, $550^{\circ} \mathrm{C}$ & 2172.234 & 780.746 & 1391.488 & 2.79 & 0.350 & 919.291 & 2.068 \\
\hline
\end{tabular}

\subsection{Yield analysis.}

BAMB-AC and BANA-AC after activation were calculated according to equation (1). Here, the yield alludes to the weight of the ACs divided by the weight of carbonized carbon with the two weights on a dry basis. The eq. 2 was demonstrated below:

$$
\text { Yield }=\frac{M}{M o} * 100 \%
$$


where $\mathrm{M}$ is the weight of carbon after activation $(\mathrm{g})$, Mo is the weight of carbon before activation $(\mathrm{g})$.

The yield of BAMB-AC $7: 1$ at $450{ }^{\circ} \mathrm{C}$ was noticed to be the highest at $18.93 \%$, the $\mathrm{H}_{3} \mathrm{PO}_{4}$ interacts in the molecular structure of broken the carbon rings down, and more special attention must be made in the whole process of activation. The dehydration of Bamboo with $\mathrm{H}_{3} \mathrm{PO}_{4}$ basically gives a higher yield of BAMB-AC at $18.93 \%$. After the dehydration process, the $-\mathrm{OH}$ and $-\mathrm{HO}$ bonds of bamboo are basically being replaced by $-\mathrm{OH}$ and $-\mathrm{HO}$ bonds of $\mathrm{H} 3 \mathrm{PO} 4$ (acid). It is basically important to note that the initial $30 \mathrm{~g}$ of bamboo gave BAMB-AC of $5.68 \mathrm{~g}[32,67]$. After drying processes of 110 at $24 \mathrm{hrs}$, the $5.68 \mathrm{~g}$ weight of BAMB-AC was summarized after the pyrolysis process at $450{ }^{\circ} \mathrm{C}$ in an $\mathrm{N} 2$ atmosphere and washing process to obtain the neutral $\mathrm{pH}$ (6-7), the other samples show low yields of AC than the BAMB-AC. Basically, it may be due to the increasing volume of volatile gases from the carbon surface when undergoing pyrolysis [68].

\section{Conclusions}

Oil spills pollutant will have many environmental effects, its ecosystem. Implementation of "preventative measures", "response technologies", as well as "decisionmaking" after an oil slick is vital which can prevent environmental oil spill pollution. Under the marine environmental conditions, the characteristic cycle is extraordinarily fast and "effortless". However, the inner systems of nature are not unending; marine climate needs appropriate treatment and security protection. It should be focused on that oil slicks and individual catastrophes are exceptionally stupendous. However, scientific research demonstrates that pollution from other sources damages the environment more. AC, synthetic adsorbents are fundamentally one of the effective applications and techniques or methodologies in the response of eliminating oil spills and effluents defilements from the environments.

The utilization of AC derived from waste biomass, BANA-AC, and BAMB-AC for oil spill response shows a promising methodology because they were very significant in determining the SA and adsorption capacity. And characterization of these materials was carried out using FTIR spectra and BET analysis. The examination shows a maximum oil adsorbed capacity at $4.418 \mathrm{~g} / \mathrm{g}$ for BANA-AC with an activation ratio 7:1 $\left(\mathrm{H}_{3} \mathrm{PO}_{4}\right)$ and $\mathrm{SA}$ at $2,172.234 \mathrm{~m}^{2} / \mathrm{g}, \mathrm{BAMB}-\mathrm{AC}\left(5: 1550{ }^{\circ} \mathrm{C}\right)$ with the highest surface area at $2,760.447 \mathrm{~m}^{2} / \mathrm{g}$, and sorption capacity range at $3.3678 \mathrm{~g} / \mathrm{g}$.

Consequently, according to the obtained results, the synthesized AC from various biomass reviews that further surface chemistry matter can prompt significantly higher remediation efficiencies since the relationship of SA to adsorption capacity has been obtained. This research provides a promising methodology for a potential option for oil spill response and possibly can be used further for pharmaceutical removal and heavy metals.

\section{Funding}

This research received no external funding.

\section{Acknowledgments}

The authors declare no acknowledgments. 


\section{Conflicts of Interest}

The authors declare no conflict of interest.

\section{References}

1. Broekema, W. Crisis-Induced Learning and Issue Politicization in the Eu: The Braer, Sea Empress, Erika, and Prestige Oil Spill Disasters. Public Administration 2016, 94, 381-398, https://doi.org/10.1111/padm.12170.

2. Singh, J.G.; Chang-Yen, I.; Stoute, V.A.; Chatergoon, L. Hydrocarbon levels in edible fish, crabs and mussels from the marine environment of Trinidad. Marine pollution bulletin 1992, 24, 270-272, https://doi.org/10.1016/0025-326X(92)90566-O.

3. Perkins, W.S.; Walsh, W.; Reed, I.; Namboodri, C. A demonstration of reuse of spent dyebath water following color removal with ozone. Textile chemist and colorist 1996, 28, 31-37.

4. Bryant, P.S.; Petersen, J.N.; Lee, J.M.; Brouns, T.M. Sorption of heavy metals by untreated red fir sawdust. Applied Biochemistry and Biotechnology 1992, 34, 777-788, https://doi.org/10.1007/BF02920596.

5. Nag, A. Utilization of charred sawdust as an adsorbent of dyes, toxic salts and oil from water. Process Safety and Environmental Protection 1995, 73, 299-304.

6. Mishra, G.; Tripathy, M. A critical review of the treatments for decolourization of textile effluent. Colourage 1993, 40, 35-35.

7. Daraei, H.; Mittal, A.; Noorisepehr, M.; Daraei, F. Kinetic and equilibrium studies of adsorptive removal of phenol onto eggshell waste. Environmental Science and Pollution Research 2013, 20, 4603-4611, https://doi.org/10.1007/s11356-012-1409-8.

8. Sayed, K.; Baloo, L.; Sharma, N.K. Bioremediation of total petroleum hydrocarbons (TPH) by bioaugmentation and biostimulation in water with floating oil spill containment booms as bioreactor basin. International Journal of Environmental Research and Public Health 2021, 18, 2226, https://doi.org/10.3390/ijerph18052226.

9. Aitani, A.M. Oil refining and products. Encyclopedia of energy 2004, 4, 715-729, https://doi.org/10.1016/B012-176480-X/00259-X.

10. Aminian, K.; Ameri, S. Evaluation of the petroleum technology-based dry soil barrier. Journal of Petroleum Science and Engineering 2000, 26, 83-89, https://doi.org/10.1016/S0920-4105(00)00023-1.

11. Doerffer, J.W. Oil spill response in the marine environment; Elsevier: 2013.

12. Mohammadi, L.; Rahdar, A.; Bazrafshan, E.; Dahmardeh, H.; Susan, M.; Hasan, A.B.; Kyzas, G.Z. Petroleum Hydrocarbon Removal from Wastewaters: A Review. Processes 2020, 8, 447, https://doi.org/10.3390/pr8040447.

13. Piperopoulos, E.; Calabrese, L.; Khaskhoussi, A.; Proverbio, E.; Milone, C. Thermo-Physical Characterization of Carbon Nanotube Composite Foam for Oil Recovery Applications. Nanomaterials 2020, 10, 86, https://doi.org/10.3390/nano10010086.

14. Zamparas, M.; Tzivras, D.; Dracopoulos, V.; Ioannides, T. Application of Sorbents for Oil Spill Cleanup Focusing on Natural-Based Modified Materials: A Review. Molecules 2020, 25, 4522, https://doi.org/10.3390/molecules25194522.

15. Kyzas, G.Z.; Matis, K.A. Nanoadsorbents for pollutants removal: a review. Journal of Molecular Liquids 2015, 203, 159-168, https://doi.org/10.1016/j.molliq.2015.01.004.

16. Kadafa A.A. Environmental Impacts of Oil Exploration and Exploitation in the Niger Delta of Nigeria. Global Journal of Science Frontier Research Environment and Earth Sciences 2012, 12, 19-28.

17. Amro, M.M. Treatment techniques of oil-contaminated soil and water aquifers. In Proceedings of the International Conf. on Water Resources \& Arid Environment 2004, 1-11.

18. Babel, S.; Kurniawan, T.A. Low-cost adsorbents for heavy metals uptake from contaminated water: a review. Journal of hazardous materials 2003, 97, 219-243, https://doi.org/10.1016/S0304-3894(02)00263-7.

19. Singh, D.; Tiwari, D.; Saksena, D. Removal of lead from aqueous solutions by chemically treated used tea leaves. Indian Journal of Environmental Health 1993, 35, 169-177.

20. Schipper, L.; Vojvodić-Vuković, M. Nitrate removal from groundwater using a denitrification wall amended with sawdust: field trial. Journal of environmental quality 1998, 27, 664-668, https://doi.org/10.2134/jeq1998.00472425002700030025x.

21. Ajmal, M.; Khan, A.H.; Ahmad, S.; Ahmad, A. Role of sawdust in the removal of copper (II) from industrial wastes. Water Research 1998, 32, 3085-3091, https://doi.org/10.1016/S0043-1354(98)00067-0.

22. Raji, C.; Anirudha, T. Chromium (VI) adsorption by sawdust carbon: Kinetics and equilibrium. Indian Journal of Chemical Technology 1997, 4, 228-236.

23. Shukla, A.; Zhang, Y.-H.; Dubey, P.; Margrave, J.; Shukla, S.S. The role of sawdust in the removal of unwanted materials from water. Journal of hazardous materials 2002, 95, 137-152, https://doi.org/10.1016/S0304-3894(02)00089-4.

24. Anirudhan, T.; Sreedhar, M. Adsorption thermodynamics of Co (II) on polysulphide treated sawdust. Indian Journal of Chemical Technology 1998, 5, 41-47.

https://biointerfaceresearch.com/ 
25. McKay, G.; Poots, V.J. Kinetics and diffusion processes in colour removal from effluent using wood as an adsorbent. Journal of Chemical Technology and Biotechnology 1980, 30, 279-292, https://doi.org/10.1002/jctb.503300134.

26. Shukla, S.; Skhardande, V. Column studies on metal ion removal by dyed cellulosic materials. Journal of applied polymer science 1992, 44, 903-910, https://doi.org/10.1002/app.1992.070440518.

27. A.T., L.; Veellu, R. Petroleum hydrocarbon along the coastal areas of Port Dickson. Petranika 1989, 12, 349355.

28. Apostolopoulos, G.; Fardis, M.; Chandrinou, C.; Giannakopoulos, K.; Kontos, A.; Bidikoudi, M.; Boukos, N.; Falaras, P.; Batzias, F.; Sidiras, D. Experimental Design of Laboratory Measurements for Hydrocarbons, Salts and Dyes Adsorption on Modified Lignocellulosic Materials in Aquatic Media. Chemical Engineering Transactions 2014, 39, 757-762.

29. Omera, A.M.; Khalifaa, R.E.; Tamera, T.M.; Alib, A.A.; Ammarc, Y.A.; Eldina, M.S.M. Kinetic and thermodynamic studies for the sorptive removal of crude oil spills using a low-cost chitosan-poly (butyl acrylate) grafted copolymer. Desalination and water treatment 2020, 192, 213-225.

30. Zang, D.; Liu, F.; Zhang, M.; Gao, Z.; Wang, C. Novel superhydrophobic and superoleophilic sawdust as a selective oil sorbent for oil spill cleanup. Chemical Engineering Research and Design 2015, 102, 34-41, https://doi.org/10.1016/j.cherd.2015.06.014.

31. Ani, J.; Akpomie, K.; Okoro, U.; Aneke, L.; Onukwuli, O.; Ujam, O. Potentials of activated carbon produced from biomass materials for sequestration of dyes, heavy metals, and crude oil components from aqueous environment. Applied Water Science 2020, 10, 1-11, https://doi.org/10.1007/s13201-020-1149-8.

32. Liakos, E.V.; Rekos, K.; Giannakoudakis, D.A.; Mitropoulos, A.C.; Kyzas, G.Z. Carbonaceous Adsorbents Derived from Agricultural Sources for the Removal of Pramipexole Pharmaceutical Model Compound from Synthetic Aqueous Solutions. Processes 2021, 9, 253, https://doi.org/10.3390/pr9020253.

33. Yorgun, S.; Yildiz, D. Preparation and characterization of activated carbons from Paulownia wood by chemical activation with H3PO4. Journal of the Taiwan Institute of Chemical Engineers 2015, 53, 122-131, https://doi.org/10.1016/j.jtice.2015.02.032.

34. Sankaranarayanan, S.; Lakshmi, D.S.; Vivekanandhan, S.; Ngamcharussrivichai, C. Biocarbons as emerging and sustainable hydrophobic/oleophilic sorbent materials for oil/water separation. Sustainable Materials and Technologies 2021, 28, e00268, https://doi.org/10.1016/j.susmat.2021.e00268.

35. Ramakrishnan, A.S.; Jayaram, R.R.; Pandimadevi, M.; Murali, H. Treatment of Oil Spill by Adsorption onto Activated Rice Husk and E-Waste. International Journal of Research in Engineering, Science and Management 2021, 4, 106-113.

36. Panahi, S.; Moghaddam, M.K.; Moezzi, M. Assessment of milkweed floss as a natural hollow oleophilic fibrous sorbent for oil spill cleanup. Journal of Environmental Management 2020, 268, 110688, https://doi.org/10.1016/j.jenvman.2020.110688.

37. Cazetta, A.L.; Vargas, A.M.; Nogami, E.M.; Kunita, M.H.; Guilherme, M.R.; Martins, A.C.; Silva, T.L.; Moraes, J.C.; Almeida, V.C. NaOH-activated carbon of high surface area produced from coconut shell: Kinetics and equilibrium studies from the methylene blue adsorption. Chemical Engineering Journal 2011, 174, 117-125, https://doi.org/10.1016/j.cej.2011.08.058.

38. Le Van, K.; Thu, T.L.T.; Thu, H.N.T.; Van Hoang, H. Activated Carbon by KOH and NaOH Activation: Preparation and Electrochemical Performance in K 2 SO 4 and Na 2 SO 4 Electrolytes. Russian Journal of Electrochemistry 2019, 55, 900-907, https://doi.org/10.1134/S1023193519070115.

39. Martins, A.F.; Cardoso, A.d.L.; Stahl, J.A.; Diniz, J. Low temperature conversion of rice husks, eucalyptus sawdust and peach stones for the production of carbon-like adsorbent. Bioresource technology 2007, 98, 1095-1100, https://doi.org/10.1016/j.biortech.2006.04.024.

40. Safar, M.; Bertrand, D.; Robert, P.; Devaux, M.F.; Genot, C. Characterization of edible oils, butters and margarines by Fourier transform infrared spectroscopy with attenuated total reflectance. Journal of the American Oil Chemists' Society 1994, 71, 371, https://doi.org/10.1007/bf02540516.

41. Pavia, D.L.; Lampman, G.M.; Kriz, G.S. Introduction to spectroscopy: a guide for students of organic chemistry. Saunders College, Orlando, FL 1996, 14.

42. El-Hendawy, A.-N.A. Variation in the FTIR spectra of a biomass under impregnation, carbonization and oxidation conditions. Journal of Analytical and Applied Pyrolysis 2006, 75, 159-166, https://doi.org/10.1016/j.jaap.2005.05.004.

43. Liu, Q.-S.; Zheng, T.; Wang, P.; Guo, L. Preparation and characterization of activated carbon from bamboo by microwave-induced phosphoric acid activation. Industrial Crops and Products 2010, 31, 233-238, https://doi.org/10.1016/j.indcrop.2009.10.011.

44. Couto, G.M.; Dessimoni, A.L.d.A.; Bianchi, M.L.; Perígolo, D.M.; Trugilho, P.F. Use of sawdust Eucalyptus sp. in the preparation of activated carbons. Ciência e Agrotecnologia 2012, 36, 69-77.

45. Gómez-Serrano, V.; Piriz-Almeida, F.; Durán-Valle, C.J.; Pastor-Villegas, J. Formation of oxygen structures by air activation. A study by FT-IR spectroscopy. Carbon 1999, 37, 1517-1528, https://doi.org/10.1016/S0008-6223(99)00025-1. 
46. Kyzas, G.Z.; Deliyanni, E.A. Modified activated carbons from potato peels as green environmental-friendly adsorbents for the treatment of pharmaceutical effluents. Chemical Engineering Research and Design 2015, 97, 135-144, https://doi.org/10.1016/j.cherd.2014.08.020.

47. Jung, M.-W.; Ahn, K.-H.; Lee, Y.; Kim, K.-P.; Rhee, J.-S.; Park, J.T.; Paeng, K.-J. Adsorption characteristics of phenol and chlorophenols on granular activated carbons (GAC). Microchemical journal 2001, 70, 123131, https://doi.org/10.1016/S0026-265X(01)00109-6.

48. Dufour, É. Chapter 1 - Principles of Infrared Spectroscopy. In Infrared Spectroscopy for Food Quality Analysis and Control, Sun, D.-W., Ed.; Academic Press: San Diego, 2009; 1-27.

49. Moharam M.A., A.L.M. A study on the effect of microwave heating on the properties of edible oils using FTIR spectroscopy. Afr. J. Microbiol. Res. 2010, 4, 1921-1927.

50. Giwa, A.; Taher, H. Dispersion-Sorption Balance (DSB) of Pickering emulsions of polydopaminepolyethylenimine-modified activated carbon for oil spill treatment. Journal of Environmental Chemical Engineering 2020, 8, 103950, https://doi.org/10.1016/j.jece.2020.103950.

51. Kohli, K.; Bhatt, N. Carbon Nanotubes-A Novel Approach to Oil Spill Cleanup. In Advances in Industrial Safety; Springer: 2020; 73-83.

52. Navarathna, C.M.; Bombuwala Dewage, N.; Keeton, C.; Pennisson, J.; Henderson, R.; Lashley, B.; Zhang, X.; Hassan, E.B.; Perez, F.; Mohan, D. Biochar adsorbents with enhanced hydrophobicity for oil spill removal. ACS applied materials \& interfaces 2020, 12, 9248-9260, https://doi.org/10.1021/acsami.9b20924.

53. Kukkar, D.; Rani, A.; Kumar, V.; Younis, S.A.; Zhang, M.; Lee, S.-S.; Tsang, D.C.; Kim, K.-H. Recent advances in carbon nanotube sponge-based sorption technologies for mitigation of marine oil spills. Journal of Colloid and Interface Science 2020, 570, 411-422, https://doi.org/10.1016/j.jcis.2020.03.006.

54. Al-Douri, Y.; Basheer, A.O. Production of powder-activated carbon from natural resources. In Nanoparticles in Analytical and Medical Devices; Elsevier: 2021; 277-299.

55. Avery, R.; Ramsay, J. The sorption of nitrogen in porous compacts of silica and zirconia powders. Journal of Colloid and Interface Science 1973, 42, 597-606, https://doi.org/10.1016/0021-9797(73)90046-5.

56. Üner, O.; Bayrak, Y. The effect of carbonization temperature, carbonization time and impregnation ratio on the properties of activated carbon produced from Arundo donax. Microporous and Mesoporous Materials 2018, 268, 225-234, https://doi.org/10.1016/j.micromeso.2018.04.037.

57. Rouquerol, J.; Rouquerol, F.; Llewellyn, P.; Maurin, G.; Sing, K.S. Adsorption by powders and porous solids: principles, methodology and applications; Academic press: 2013.

58. Fernandez, M.E.; Nunell, G.V.; Bonelli, P.R.; Cukierman, A.L. Activated carbon developed from orange peels: Batch and dynamic competitive adsorption of basic dyes. Industrial Crops and Products 2014, 62, 437445, https://doi.org/10.1016/j.indcrop.2014.09.015.

59. Thommes, M.; Kaneko, K.; Neimark, A.V.; Olivier, J.P.; Rodriguez-Reinoso, F.; Rouquerol, J.; Sing, K.S. Physisorption of gases, with special reference to the evaluation of surface area and pore size distribution (IUPAC Technical Report). Pure and applied chemistry 2015, 87, 1051-1069, https://doi.org/10.1515/pac2014-1117.

60. Brunauer, S.; Deming, L.S.; Deming, W.E.; Teller, E. On a theory of the van der Waals adsorption of gases. Journal of the American Chemical society 1940, 62, 1723-1732, https://doi.org/10.1021/ja01864a025.

61. Zhang, T.; Walawender, W.P.; Fan, L.; Fan, M.; Daugaard, D.; Brown, R. Preparation of activated carbon from forest and agricultural residues through $\mathrm{CO} 2$ activation. Chemical Engineering Journal 2004, 105, 5359, https://doi.org/10.1016/j.cej.2004.06.011.

62. Tuli, F.J.; Hossain, A.; Kibria, A.K.M.F.; Tareq, A.R.M.; Mamun, S.M.M.A.; Ullah, A.K.M.A. Removal of methylene blue from water by low-cost activated carbon prepared from tea waste: A study of adsorption isotherm and kinetics. Environmental Nanotechnology, Monitoring \& Management 2020, 14, 100354, https://doi.org/10.1016/j.enmm.2020.100354.

63. Liakos, E.V.; Rekos, K.; Giannakoudakis, D.A.; Mitropoulos, A.C.; Fu, J.; Kyzas, G.Z. Activated Porous Carbon Derived from Tea and Plane Tree Leaves Biomass for the Removal of Pharmaceutical Compounds from Wastewaters. Antibiotics 2021, 10, 65, https://doi.org/10.3390/antibiotics10010065.

64. Lippens, B.C.; De Boer, J. Studies on pore systems in catalysts: V. The t method. Journal of Catalysis $\mathbf{1 9 6 5 ,}$ 4, 319-323, https://doi.org/10.1016/0021-9517(65)90307-6.

65. Moosavi, S.; Lai, C.W.; Akbarzadeh, O.; Johan, M.R. Recycled Activated Carbon-Based Materials for the Removal of Organic Pollutants from Wastewater. Waste Recycling Technologies for Nanomaterials Manufacturing 2021, 513-539, https://doi.org/10.1007/978-3-030-68031-2_18.

66. Dhaka, A.; Chattopadhyay, P. A review on physical remediation techniques for treatment of marine oil spills. Journal of Environmental Management 2021, 288, 112428.

67. Thakur, A.K.; Sathyamurthy, R.; Sharshir, S.W.; Elkadeem, M.; Ma, Z.; Manokar, A.M.; Arıcı, M.; Pandey, A.; Saidur, R. Performance analysis of a modified solar still using reduced graphene oxide coated absorber plate with activated carbon pellet. Sustainable Energy Technologies and Assessments 2021, 45, 101046, https://doi.org/10.1016/j.seta.2021.101046.

68. Betar, B.O.; Alsaadi, M.A.; Chowdhury, Z.Z.; Aroua, M.K.; Mjalli, F.S.; Niazi, M. High Yield SuperHydrophobic Carbon Nanomaterials Using Cobalt/Iron Co-Catalyst Impregnated on Powder Activated Carbon. Processes 2021, 9, 134, https://doi.org/10.3390/pr9010134. 